\title{
A Range Adjusted Measure of Super-Efficiency in Integer-Valued Data Envelopment Analysis with Undesirable Outputs
}

\author{
Chunhua CHEN \\ School of Business Administration, Jiangxi University of Finance and Economics, Nanchang 330013, \\ China; Inner Mongolia Branch of Agricultural Bank of China, Hohhot 010010, China \\ E-mail: nmgchenchunhua@126.com \\ Haohua LIU \\ School of Business Administration, Jiangxi University of Finance and Economics, Nanchang 330013, \\ China \\ E-mail: jxliuhaohua@126.com \\ Lijun TANG \\ Plymouth Business School, University of Plymouth, Plymouth PL48AA, United Kingdom \\ E-mail: lijun.tang@plymouth.ac.uk \\ Jianwei REN* \\ Transportation Institute, Inner Mongolia University, Hohhot 010070, China; School of Mathematical \\ Sciences, Inner Mongolia University, Hohhot 010010, China \\ E-mail: renjianwei309@126.com
}

\begin{abstract}
DEA (data envelopment analysis) models can be divided into two groups: Radial DEA and non-radial DEA, and the latter has higher discriminatory power than the former. The range adjusted measure (RAM) is an effective and widely used non-radial DEA approach. However, to the best of our knowledge, there is no literature on the integer-valued super-efficiency RAM-DEA model, especially when undesirable outputs are included. We first propose an integer-valued RAM-DEA model with undesirable outputs and then extend this model to an integer-valued super-efficiency RAM-DEA model with undesirable outputs. Compared with other DEA models, the two novel models have many advantages: 1) They are non-oriented and non-radial DEA models, which enable decision makers to simultaneously and non-proportionally improve inputs and outputs; 2) They can handle integer-valued variables and undesirable outputs, so the results obtained are more reliable; 3) The results can be easily obtained as it is based on linear programming; 4) The integer-valued super-efficiency RAM-DEA model with undesirable outputs can be used to accurately rank efficient DMUs. The proposed models are applied to evaluate the efficiency of China's regional transportation systems (RTSs) considering the

Received July 24, 2020, accepted November 11, 2020

Supported by the National Natural Science Foundation of China (71862026), the China Postdoctoral Science Foundation (2018T110209), the Natural Science Foundation of Inner Mongolia (2018MS07006), the "13th Five Year" Plan of Educational Science Research in Inner Mongolia (NGJGH2018016), and the State Scholarship Fund of China Scholarship Council (20180815502)

${ }^{*}$ Corresponding author
\end{abstract}


number of transport accidents (an undesirable output). The results help decision makers improve the performance of inefficient RTSs and analyze the strengths of efficient RTSs.

Keywords DEA; range adjusted measure (RAM); super-efficiency; undesirable outputs; transport

\section{Introduction}

Data envelopment analysis (DEA) is generally regarded as an effective nonparametric technique to evaluate the relative efficiency (performance) of decision making units (DMUs) ${ }^{[1,2]}$. DEA models can be divided into two groups: Radial DEA and non-radial DEA ${ }^{[3,4]}$. Radial DEA models, i.e., the CCR model by Charnes, et al. ${ }^{[5]}$ and the BCC model by Banker, et al. ${ }^{[6]}$, only allow proportional reductions of inputs or increases of outputs to improve the performance of DMUs, while non-radial DEA models enable non-proportional changes of inputs and outputs ${ }^{[7]}$. Thus, non-radial DEA models have higher discriminatory power than radial DEA models ${ }^{[8,9]}$.

There are several types of non-radial DEA models including additive DEA ${ }^{[10]}$, slacks-based measure $(\mathrm{SBM})^{[11]}$, and range adjusted measure $(\mathrm{RAM})^{[12]}$. Additive DEA models, however, have a weakness: They cannot generate efficiency scores for DMUs ${ }^{[13]}$. To address this weakness, RAM-DEA and SBM-DEA are developed based on the additive DEA. While both of them have all the advantages of additive DEA, they are also able to generate efficiency scores. Therefore, they have been applied to various situations ${ }^{[14]}$. In this paper, we apply the RAM-DEA because integer-valued RAM-DEA models are linear programming while integer-valued SBMDEA models are nonlinear programming even after the Charnes-Cooper transformation ${ }^{[15,16]}$. In the context that many inputs and outputs, for example, the number of employees, machines, gold medals, transport accidents and so on, can only be integer values in reality, integer-valued variables have to be taken into account. As real-valued DEA models cannot deal with integervalued variables, integer-valued DEA models have been developed to address the issue ${ }^{[17-19]}$. Lozano and Villa were the first to propose a mixed integer linear programming (MILP) DEA model to restrict variables to integers ${ }^{[17]}$, but this model is not consistent with the minimum extrapolation principle. To tackle this problem, Kuosmanen and Matin developed a novel axiomatic foundation for integer-valued DEA models that assumes subsets of input and output variables to be integer-valued ${ }^{[19]}$. As far as we know, there is no literature on integer-valued RAM-DEA models. All the RAM-DEA models discussed below are real-valued DEA models.

Cooper, et al. presented the first RAM-DEA model and analyzed its advantages at the Georgia Productivity Workshop in 1996, and their paper was published in 1999 ${ }^{[12]}$. Aida, et al. tested the robustness of the RAM-DEA model and applied this model to estimate the performance of water supply services in Japan ${ }^{[20]}$. Steinmann and Zweifel ${ }^{[21]}$ as well as Cooper, et al. ${ }^{[22]}$ also studied the properties of the RAM-DEA model. Sueyoshi and Sekitani proposed the measurement of returns to scale using a RAM-DEA model ${ }^{[23]}$. Based on the RAM-DEA, Cooper, et al. developed a bounded adjusted measure (BAM) DEA model that considered lower bounds for inputs and upper bounds for outputs ${ }^{[24]}$. Chiu, et al. proposed a context-dependent RAM-DEA model to evaluate the relative attractiveness and progress efficiency of Taiwanese commercial banks ${ }^{[25]}$. Avkiran and McCrystal presented a dynamic network RAM-DEA model ${ }^{[26]}$. Tavassoli, et al. developed a RAM-SCSC-DEADA approach to 
rank Iranian airlines, where the SCSC indicated the strong complementary slackness condition and the DEADA represented the DEA discriminant analysis ${ }^{[27]}$. Liu, et al. proposed a closest RAM-DEA model to evaluate the performance of coal-fired power plants in China ${ }^{[28]}$. Li, et al. presented a virtual frontier dynamic RAM-DEA model to measure the energy efficiency of airlines ${ }^{[29]}$. Wanke and Barros also applied a virtual frontier dynamic RAM-DEA model to measure the performance of Latin American airlines ${ }^{[30]}$. Li, et al. developed an input-shared network RAM-DEA model to evaluate the efficiency of several airlines ${ }^{[31]}$.

The aforementioned RAM-DEA models did not take undesirable outputs into account. However, in reality, many production activities generate undesirable outputs that should be reduced as much as possible. Many researchers have proved that it is necessary to consider undesirable outputs when evaluating the efficiency of DMUs with undesirable outputs ${ }^{[2,33]}$. Sueyoshi and Goto first proposed a RAM-DEA model with undesirable outputs (RAM-UDEA) ${ }^{[34,35]}$. Ramli and Munisamy applied a RAM-UDEA model to evaluate the eco-efficiency of the manufacturing industry in Malaysia ${ }^{[36]}$. Wang and Yu developed a RAM-UDEA model to estimate the industrial energy and environmental performance of Chinese cities ${ }^{[37]}$. Wang, et al. presented a RAM-UDEA model to measure the innovation and environment performance of China's manufacturing industry ${ }^{[38]}$. Cui and Li proposed a network RAM-UDEA model with weak-G disposability to evaluate the environmental performance of several airlines ${ }^{[39]}$. Meng, et al. applied a RAM-UDEA model to estimate the low-carbon economy performance of China's provinces ${ }^{[0]}$. Kang, et al. presented a RAM-UDEA model with natural and managerial disposability to measure the energy and environmental performance of the manufacturing industry in China ${ }^{[11]}$. Miao, et al. studied the joint decomposition of RAM-UDEA and Luenberger productivity indicators and applied this approach to evaluate the atmospheric environmental performance in China ${ }^{[42]}$. Eftekharian, et al. proposed a RAM-UDEA model to measure the environmental efficiency of industrial industries in Iran ${ }^{[43]}$. Wang and Yuan proposed a RAM-UDEA model to measure the energy and $\mathrm{CO}_{2}$ (carbon dioxide) emission efficiencies of cigarette companies in China ${ }^{[44]}$. Chen, et al. used the RAM-UDEA approach to compare congestion effects of 46 countries along the Belt and Road ${ }^{[45]}$. Yuan, et al. presented a RAM-UDEA model to assess the inclusive and sustainable industrial development in China ${ }^{[46]}$.

However, conventional radial and non-radial DEA models cannot be used to distinguish better performers from efficient DMUs because the efficiency scores of all efficient DMUs must be equal to 1 . To differentiate the efficient DMUs, it is necessary to measure super-efficiency. Super-efficiency DEA models can be developed by removing the DMU under evaluation from the reference set ${ }^{[47,48]}$ allowing their efficiency (super-efficiency) scores greater than one. In this way, decision makers can rank the efficient DMUs based on their super-efficiency scores. Andersen and Petersen proposed the first radial super-efficiency DEA model ${ }^{[49]}$. Radial superefficiency DEA models can only proportionally change inputs and outputs and therefore their discriminatory ability is weaker than non-radial super-efficiency DEA models ${ }^{[50,51]}$. In the field of non-radial super-efficiency DEA, Du, et al. ${ }^{[52]}$, Guo, et al. ${ }^{[53]}$, Yu and Hsu ${ }^{[54]}$, among others studied super-efficiency additive DEA models, and Tone ${ }^{[55]}$, Tran, et al. ${ }^{[56]}$, Chen, et al. ${ }^{[57]}$, and many other scholars researched super-efficiency SBM-DEA models. Many studies show that super-efficiency additive DEA models are always feasible while conventional radial super- 
efficiency DEA models would be infeasible under the assumption of VRS (Variable Returns to Scale) $)^{[52,54]}$.

To the best of our knowledge, however, there is no literature on the super-efficiency RAMDEA model, especially when both integer-valued variables and undesirable outputs are included. Therefore, in this paper we propose an integer-valued super-efficiency RAM-DEA model with undesirable outputs (Super-RAM-IUDEA) and apply the model to evaluate the efficiency of China's regional transportation systems considering the number of transport accidents (an undesirable output). The conceptual model of our research is shown in Figure 1. To propose the Super-RAM-IUDEA we first develop an integer-valued RAM-DEA model with undesirable outputs (RAM-IUDEA). The main advantages of the two novel models are: 1) They are nonoriented and non-radial DEA models, which enable decision makers to simultaneously and non-proportionally improve inputs and outputs; 2) They can handle integer-valued variables and undesirable outputs, and as such the results obtained from our model are more reliable; 3 ) The results can be easily obtained because the model is based on linear programming; (4) the Super-RAM-IUDEA model can be used to accurately rank efficient DMUs.

The remaining of this paper is organized as follows. The RAM-IUDEA and Super-RAMIUDEA models are presented in Section 2. The proposed models are applied to evaluate the efficiency (super-efficiency) of China's regional transportation systems in Section 3. A concluding comment and the limitation of this research are summarized in Section 4. We also highlight the contributions of this paper in the last section.

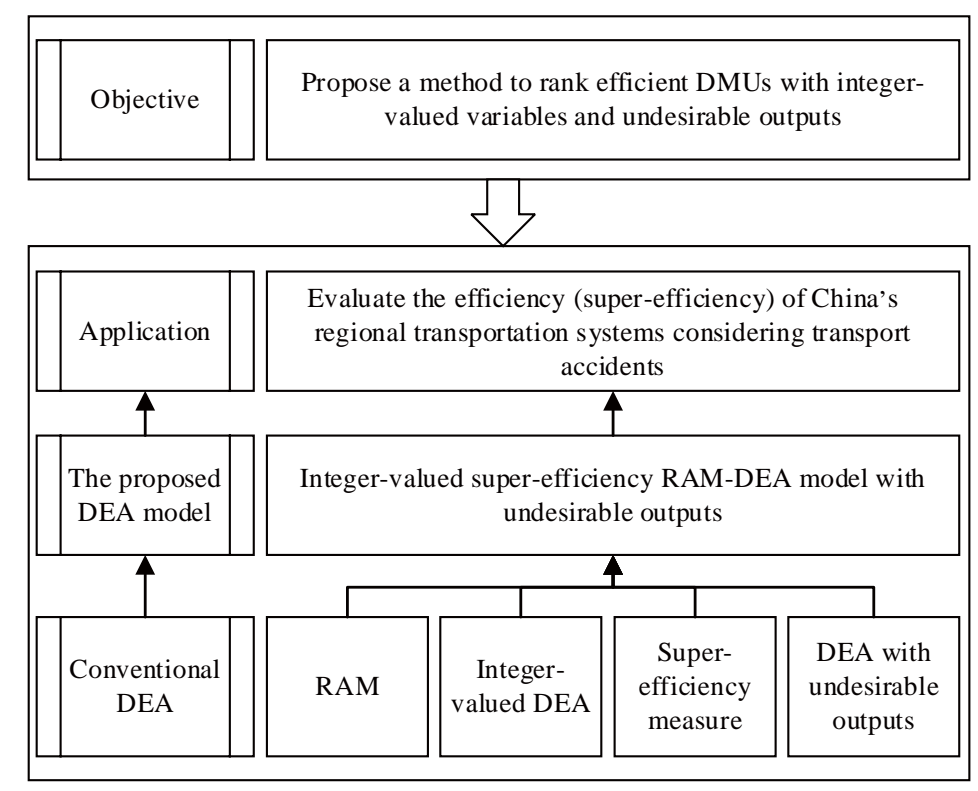

Figure 1 The conceptual model of this research

\section{Methodology}

Consider that we have $q$ DMUs $\left(\mathrm{DMU}_{i}, i=1,2, \cdots, q\right)$ and each DMU uses $r$ inputs to produce $m$ desirable outputs as well as $t$ undesirable outputs. In addition, some of these variables 
can only be integers. Let $x_{j i}(j=1,2, \cdots, g), x_{j i}(j=g+1, g+2, \cdots, r), y_{p i}(p=1,2, \cdots, o)$, $y_{p i}(p=o+1, o+2, \cdots, m), z_{h i}(h=1,2, \cdots, e)$, and $z_{h i}(h=e+1, e+2, \cdots, t)$ denote DMU ${ }_{i}$ 's integer-valued inputs, real-valued inputs, integer-valued desirable outputs, real-valued desirable outputs, integer-valued undesirable outputs, and real-valued undesirable outputs, respectively.

\subsection{Classic Additive DEA Model and Range Adjusted Measure}

Charnes, et al. first proposed model (1) to evaluate the performance of $\mathrm{DMU}_{k}$ (the DMU under evaluation) in $1985^{[10]}$. The model was named "additive DEA model" because its objective is to maximize the sum of all slacks. This model simultaneously deals with the slacks for inputs and desirable outputs, so it can identify all inefficiencies in inputs and desirable outputs $^{[10]}$.

$$
\begin{array}{ll}
\max & s_{j}^{-}+s_{p}^{+} \\
\text {s.t. } & \sum_{i=1}^{q} x_{j i} \lambda_{i}=x_{j k}-s_{j}^{-}, \quad j=1,2, \cdots, r, \\
& \sum_{i=1}^{q} y_{p i} \lambda_{i}=y_{p k}+s_{p}^{+}, \quad p=1,2, \cdots, m, \\
& \sum_{i=1}^{q} \lambda_{i}=1, \\
& \lambda_{i}, s_{j}^{-}, s_{p}^{+} \geq 0 \text { for all } i, j, p,
\end{array}
$$

where $s_{j}^{-}$indicates the slack related to the $j$ th input; $s_{p}^{+}$denotes the slack related to the $p$ th

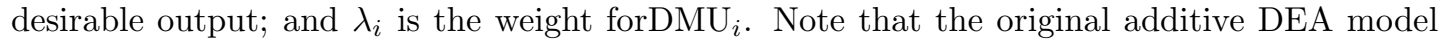
proposed by Charnes, et al. is under the CRS (constant returns to scale) condition while model (1) assumes VRS (variable returns to scale) ${ }^{[10]}$. The original CRS additive DEA model can be obtained by deleting $\sum_{i=1}^{q} \lambda_{i}=1$ from model (1). According to model (1), $\mathrm{DMU}_{k}$ is efficient if and only if all slacks equal to $0\left(s_{j}^{-*}=s_{p}^{+*}=0\right)$. We let the superscript $*$ indicate the optima obtained from DEA models. Obviously, model (1) cannot generate efficiency scores for DMUs. In addition, it treats integer-valued variables as real-valued variables and cannot deal with undesirable outputs. Therefore, this model is not good enough for our problem.

Cooper, et al. developed the RAM-DEA model (model (2)) based on the additive DEA model, which maximized the weighted sum of all slacks ${ }^{[12]}$. Different from the additive DEA model, the RAM-DEA model can generate efficiency scores. $\theta_{k}^{*}$ is the efficiency score of DMU $\mathrm{D}$. Moreover, the RAM-DEA model has five properties that should be satisfied. 1) $0 \leq \theta_{k}^{*} \leq 1$, which means that the efficiency scores obtained from model (2) are between zero and one. 2) $\theta_{k}^{*}=1\left(s_{j}^{-*}=s_{p}^{+*}=0\right)$ if and only if $\mathrm{DMU}_{k}$ is fully Pareto-Koopmans efficient. 3) $\theta_{k}^{*}$ is invariant to the units of inputs and outputs and invariant to alternative optima. 4) $\theta_{k}^{*}$ is invariant to transformation $\left(\theta_{k}^{*}\right.$ is not affected by a change in the origin of coordinate values). 5)

$\theta_{k}^{*}$ has strong monotonicity ${ }^{[20-22]}$. However, model (2) cannot handle integer-valued variables or undesirable outputs. Therefore, we update this model and extend the updated RAM-DEA model to a super-efficiency RAM-DEA model. 


$$
\begin{array}{ll}
\min & \theta_{k}=1-\frac{1}{r+m}\left(\sum_{j=1}^{r} \frac{s_{j}^{-}}{R_{j}^{-}}+\sum_{p=1}^{m} \frac{s_{p}^{+}}{R_{p}^{+}}\right) \\
\text {s.t. } & \sum_{i=1}^{q} x_{j i} \lambda_{i}=x_{j k}-s_{j}^{-}, \quad j=1,2, \cdots, r, \\
& \sum_{i=1}^{q} y_{p i} \lambda_{i}=y_{p k}+s_{p}^{+}, \quad p=1,2, \cdots, m, \\
& \sum_{i=1}^{q} \lambda_{i}=1, \\
& \lambda_{i}, s_{j}^{-}, s_{p}^{+} \geq 0 \text { for all } i, j, p,
\end{array}
$$

where $R_{j}^{-}=\max _{i}\left\{x_{j i}\right\}-\min _{i}\left\{x_{j i}\right\}$ is the range of the $j$ th input and $R_{p}^{+}=\max _{i}\left\{y_{p i}\right\}-$ $\min _{i}\left\{y_{p i}\right\}$ is the range of the $p$ th desirable output. The other mathematical notations are the same as those in model (1).

\subsection{Integer-Valued RAM-DEA Model with Undesirable Outputs}

Suppose $x_{j i} \in X^{I}(j=1,2, \cdots, g), y_{p i} \in Y^{I}(p=1,2, \cdots, o), z_{h i} \in Z^{I}(h=1,2, \cdots, e)$, $x_{j i} \in X^{N I}(j=g+1, g+2, \cdots, r), y_{p i} \in Y^{N I}(p=o+1, o+2, \cdots, m)$, and $z_{h i} \in Z^{N I}$ $(h=e+1, e+2, \cdots, t)$, where $X^{I} \in \mathbb{Z}_{+}^{g}, Y^{I} \in \mathbb{Z}_{+}^{o}, Z^{I} \in \mathbb{Z}_{+}^{e}$ indicate the subsets of corresponding integer-valued variables while $X^{N I}, Y^{N I}, Z^{N I}$ denote the subsets of corresponding real-valued variables. Then, the DEA production possibility set (PPS) assuming VRS for our problem can be represented by

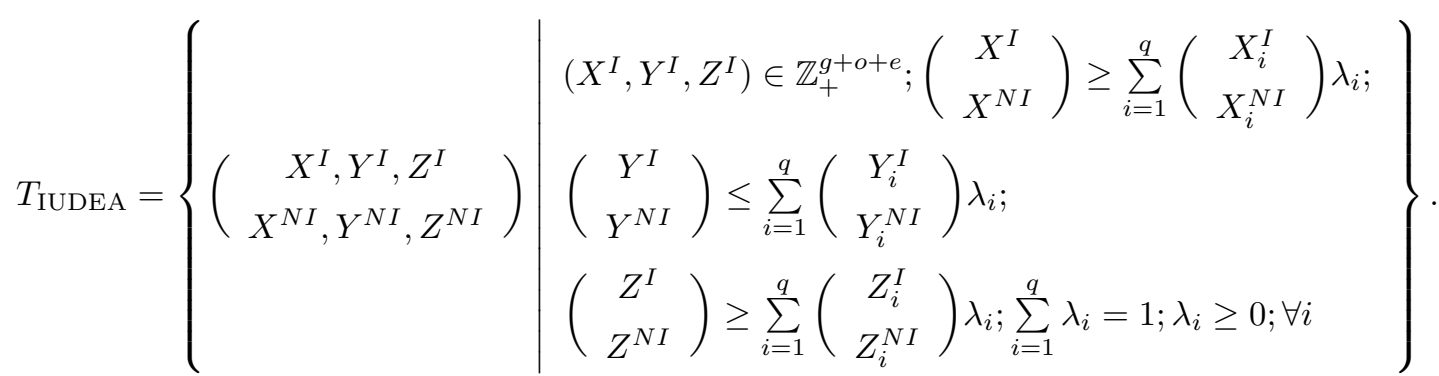

The efficiency score of $\mathrm{DMU}_{k}$ relative to the $T_{\text {IUDEA }}$ reference technology can be computed by solving the proposed integer-valued RAM-DEA model with undesirable outputs (RAMIUDEA, model 4). In the model, $\lambda_{i}$ is the weight of $\mathrm{DMU}_{i} ; R_{j}^{-}=\max _{i}\left\{x_{j i}\right\}-\min _{i}\left\{x_{j i}\right\}$ is the range of the $j$ th input; $R_{p}^{+}=\max _{i}\left\{y_{p i}\right\}-\min _{i}\left\{y_{p i}\right\}$ is the range of the $p$ th desirable output; $R_{h}^{-}=\max _{i}\left\{z_{h i}\right\}-\min _{i}\left\{z_{h i}\right\}$ is the range of the $h$ th undesirable output; $s_{j}^{I-}, s_{j}^{-}, s_{p}^{I+}, s_{p}^{+}, \varsigma_{h}^{I-}$, and $\varsigma_{h}^{-}$indicate the slacks related to integer-valued inputs, real-valued inputs, integer-valued desirable outputs, real-valued desirable outputs, integer-valued undesirable outputs, and realvalued undesirable outputs, respectively; $\mathbb{Z}$ is the set of integer values and therefore $s_{j}^{I-*}, s_{p}^{I+*}$, and $\varsigma_{h}^{I-*}$ must be integers.

Model (4) has all the advantages of the classic RAM-DEA model and is able to identify all inefficiencies in integer-valued and real-valued inputs, integer-valued and real-valued desirable outputs, and integer-valued and real-valued undesirable outputs. Note that we use the slacksbased measure (SBM) approach $\left(\sum_{i=1}^{q} z_{h i} \lambda_{i} \leq z_{h k}-\varsigma_{h}^{I-}, h=1,2, \cdots, e ; \sum_{i=1}^{q} z_{h i} \lambda_{i}=z_{h k}-\right.$ 
$\varsigma_{h}^{-}, h=e+1, e+2, \cdots, t$, where $\varsigma_{h}^{I-}$ and $\varsigma_{h}^{-}$are the slacks related to integer-valued undesirable outputs and real-valued undesirable outputs, respectively) and formulate RAM-DEA models to handle undesirable outputs ${ }^{[58]}$. There are several approaches to deal with undesirable outputs, such as the assumption of weak disposability proposed by Färe, et al. ${ }^{[59]}$, direction distance function (DDF) suggested by Chung, et al. ${ }^{[60,61]}$, linear or non-linear monotonic decreasing transformation ${ }^{[62,63]}$, and treating undesirable outputs as inputs ${ }^{[13]}$. Compared with these approaches, the SBM approach is simple and easy to understand ${ }^{[58]}$. The constraints related to integer-valued variables are inequalities because $\sum_{i=1}^{q} x_{j i} \lambda_{i}^{*}, \sum_{i=1}^{q} y_{p i} \lambda_{i}^{*}$, and $\sum_{i=1}^{q} z_{h i} \lambda_{i}^{*}$ may not be integers (where $0 \leq \lambda_{i}^{*} \leq 1$ ) while $x_{j k}-s_{j}^{I-*}, y_{p k}+s_{p}^{I+*}$, and $z_{h k}-\varsigma_{h}^{I-*}$ must be integers. This method can effectively deal with integer-valued variables when measuring efficiency, so it has been widely used ${ }^{[52,64]}$.

$$
\begin{array}{ll}
\min \quad & \theta_{k}=1-\frac{\sum_{j=1}^{g} \frac{s_{j}^{I-}}{R_{j}^{-}}+\sum_{j=g+1}^{r} \frac{s_{j}^{-}}{R_{j}^{-}}+\sum_{p=1}^{o} \frac{s_{p}^{I+}}{R_{p}^{+}}+\sum_{p=o+1}^{m} \frac{s_{p}^{+}}{R_{p}^{+}}+\sum_{h=1}^{e} \frac{\varsigma_{h}^{I-}}{R_{h}^{-}}+\sum_{h=e+1}^{t} \frac{\varsigma_{h}^{-}}{R_{h}^{-}}}{r+m+t} \\
\text { s.t. } \quad & \sum_{i=1}^{q} x_{j i} \lambda_{i} \leq x_{j k}-s_{j}^{I-}, \quad j=1,2, \cdots, g, \\
& \sum_{i=1}^{q} x_{j i} \lambda_{i}=x_{j k}-s_{j}^{-}, \quad j=g+1, g+2, \cdots, r, \\
& \sum_{i=1}^{q} y_{p i} \lambda_{i} \geq y_{p k}+s_{p}^{I+}, \quad p=1,2, \cdots, o, \\
& \sum_{i=1}^{q} y_{p i} \lambda_{i}=y_{p k}+s_{p}^{+}, \quad p=o+1, o+2, \cdots, m, \\
& \sum_{i=1}^{q} z_{h i} \lambda_{i} \leq z_{h k}-\varsigma_{h}^{I-}, \quad h=1,2, \cdots, e, \\
& \sum_{i=1}^{q} z_{h i} \lambda_{i}=z_{h k}-\varsigma_{h}^{-}, \quad h=e+1, e+2, \cdots, t, \\
& \sum_{i=1}^{q} \lambda_{i}=1, \\
& \lambda_{i}, s_{j}^{I-}, s_{j}^{-}, s_{p}^{I+}, s_{p}^{+}, \varsigma_{h}^{I-}, \varsigma_{h}^{-} \geq 0 \text { for all } i, j, p, h, \\
& s_{j}^{I-} \in \mathbb{Z}, \quad j=1,2, \cdots, g, \\
& s_{p}^{I+} \in \mathbb{Z}, \quad p=1,2, \cdots, o, \\
& \varsigma_{h}^{I-} \in \mathbb{Z}, \quad h=1,2, \cdots, e .
\end{array}
$$

Model (4) is the first RAM-DEA model that can deal with undesirable outputs and integervalued variables. The main advantages of the novel model are: 1) It is a non-oriented and nonradial DEA model, which enables decision makers to simultaneously and non-proportionally improve inputs and outputs; 2) It can handle integer-valued variables and undesirable outputs, and as such the results obtained from our model are more reliable; 3) The results can be easily obtained because the model is based on linear programming.

Proposition $1 \mathrm{DMU}_{k}$ is efficient if and only if $\theta_{k}^{*}=1$ and all slacks equal to $0\left(s_{j}^{I-*}=\right.$ $\left.s_{j}^{-*}=s_{p}^{I+*}=s_{p}^{+*}=\varsigma_{h}^{I-*}=\varsigma_{h}^{-*}=0\right)$. 
Proposition $2 \mathrm{DMU}_{k}$ is inefficient if and only if $\theta_{k}^{*}<1$.

Proposition 3 The greater $\theta_{k}^{*}$ is, the better the performance of $\mathrm{DMU}_{k}$ would be.

Proof 1) If $s_{j}^{I-*}=s_{j}^{-*}=s_{p}^{I+*}=s_{p}^{+*}=\varsigma_{h}^{I-*}=\varsigma_{h}^{-*}=0$, then we have $\sum_{i=1}^{q} x_{j i} \lambda_{i}^{*}+\varepsilon_{j}^{I-}=$ $x_{j k}$ for $j=1,2, \cdots, g, \quad \sum_{i=1}^{q} x_{j i} \lambda_{i}^{*}=x_{j k}$ for $j=g+1, g+2, \cdots, r, \quad \sum_{i=1}^{q} y_{p i} \lambda_{i}^{*}-\varepsilon_{p}^{I+}=y_{p k}$ for $p=1,2, \cdots, o, \quad \sum_{i=1}^{q} y_{p i} \lambda_{i}^{*}=y_{p k}$ for $p=o+1, o+2, \cdots, m, \sum_{i=1}^{q} z_{h i} \lambda_{i}^{*}+\varepsilon_{h}^{I-}=z_{h k}$ for $h=1,2, \cdots, e$, and $\sum_{i=1}^{q} z_{h i} \lambda_{i}^{*}=z_{h k}$ for $h=e+1, e+2, \cdots, t$, which means that $\mathrm{DMU}_{k}$ is on the efficient frontier (the production possibility frontier). Therefore, $\mathrm{DMU}_{k}$ is efficient. $\varepsilon_{j}^{I-}$, $\varepsilon_{p}^{I+}, \varepsilon_{h}^{I-}$ are used to make $\sum_{i=1}^{q} x_{j i} \lambda_{i}^{*}+\varepsilon_{j}^{I-}, \sum_{i=1}^{q} y_{p i} \lambda_{i}-\varepsilon_{p}^{I+}, \sum_{i=1}^{q} z_{h i} \lambda_{i}^{*}+\varepsilon_{h}^{I-}$ integers. This method makes the efficient frontier of DMUs with integer-valued variables more reliable ${ }^{[17-19]}$. Note that $\theta_{k}^{*}=1$ if and only if all slacks equal to 0 . Therefore, $\mathrm{DMU}_{k}$ is efficient if $\theta_{k}^{*}=1$ and all slacks equal to 0 .

$s_{j}^{I-*} \neq 0, s_{j}^{-*} \neq 0, s_{p}^{I+*} \neq 0, s_{p}^{+*} \neq 0, \varsigma_{h}^{I-*} \neq 0$, and $\varsigma_{h}^{-*} \neq 0$, which imply $\theta_{k}^{*} \neq$ 1 , indicate that $\mathrm{DMU}_{k}$ can move to the efficient frontier by reducing integer-valued inputs, cutting down on real-valued inputs, increasing integer-valued desirable outputs, increasing realvalued desirable outputs, reducing integer-valued undesirable outputs, and reducing real-valued undesirable outputs, respectively. Thus, $\mathrm{DMU}_{k}$ is inefficient. We have proved that $\mathrm{DMU}_{k}$ is efficient only if $\theta_{k}^{*}=1$ and all slacks equal to 0 . Proposition 1 has been proved.

2) There must be $\theta_{k}^{*} \leq 1$ for model (4) because we have $0 \leq s_{j}^{I-*} \leq x_{j k}-\sum_{i=1}^{q} x_{j i} \lambda_{i}^{*} \leq$ $R_{j}^{-}$for $j=1,2, \cdots, g, \quad 0 \leq s_{j}^{-*}=x_{j k}-\sum_{i=1}^{q} x_{j i} \lambda_{i}^{*} \leq R_{j}^{-}$for $j=g+1, g+2, \cdots, r$, $0 \leq s_{p}^{I+*} \leq \sum_{i=1}^{q} y_{p i} \lambda_{i}^{*}-y_{p k} \leq R_{p}^{+}$for $p=1,2, \cdots, o, 0 \leq s_{p}^{+*}=\sum_{i=1}^{q} y_{p i} \lambda_{i}^{*}-y_{p k} \leq R_{p}^{+}$ for $p=o+1, o+2, \cdots, m, \quad 0 \leq \varsigma_{h}^{I-*} \leq z_{h k}-\sum_{i=1}^{q} z_{h i} \lambda_{i}^{*} \leq R_{h}^{-}$for $h=1,2, \cdots, e$, and $0 \leq \varsigma_{h}^{-*}=z_{h k}-\sum_{i=1}^{q} z_{h i} \lambda_{i}^{*} \leq R_{h}^{-}$for $h=e+1, e+2, \cdots, t$. Proposition 2 is valid because we also have Proposition 1.

3) The greater $\theta_{k}^{*}$ (the less the second part of the right side of the objective function in model 4) is, the shorter the distance between $\mathrm{DMU}_{k}$ and the efficient frontier would be, which indicates that there are less waste on inputs, less shortage in desirable outputs, and less undesirable outputs in $\mathrm{DMU}_{k}$. Therefore, the greater $\theta_{k}^{*}$ is, the better the performance of $\mathrm{DMU}_{k}$ would be.

To achieve efficiency, decision makers can set targets to eliminate slacks. The targets for $\mathrm{DMU}_{k}$ 's integer-valued inputs, real-valued inputs, integer-valued desirable outputs, real-valued desirable outputs, integer-valued undesirable outputs, and real-valued undesirable outputs can be calculated using equations (5), (6), (7), (8), (9), and (10), respectively. In this approach, integer-valued targets for integer-valued variables can be obtained because the slacks for integervalued variables are integers $\left(s_{j}^{I-*} \in \mathbb{Z}, s_{p}^{I+*} \in \mathbb{Z}, \varsigma_{h}^{I-*} \in \mathbb{Z}\right)$.

$$
\begin{aligned}
& \bar{x}_{j k}=x_{j k}-s_{j}^{I-*}, \quad j=1,2, \cdots, g, \\
& \bar{x}_{j k}=x_{j k}-s_{j}^{-*}, \quad j=g+1, g+2, \cdots, r \\
& \bar{y}_{p k}=y_{p k}+s_{p}^{I+*}, \quad p=1,2, \cdots, o \\
& \bar{y}_{p k}=y_{p k}+s_{p}^{+*}, \quad p=o+1, o+2, \cdots, m, \\
& \bar{z}_{h k}=z_{h k}-\varsigma_{h}^{I-*}, \quad h=1,2, \cdots, e
\end{aligned}
$$




$$
\bar{z}_{h k}=z_{h k}-\varsigma_{h}^{-*}, \quad h=e+1, e+2, \cdots, t .
$$

\subsection{Integer-Valued Super-Efficiency RAM-DEA Model with Undesirable Outputs}

However, as the efficiency scores of all efficient DMUs must equal to one, it is impossible to differentiate efficient DMUs using model (4). To develop an integer-valued super-efficiency RAM-DEA model with undesirable outputs (Super-RAM-IUDEA), we cannot just delete the evaluated DMU from the reference set because the model may be infeasible for efficient DMUs if we do so. In this context, we develop model (11) to calculate the super-efficiency score $\varphi_{k}^{*}$ of efficient $\mathrm{DMU}_{k}$. In the model, $\xi_{j}^{I-}, \xi_{j}^{-}, \xi_{p}^{I+}, \xi_{p}^{+}, \tau_{h}^{I-}$, and $\tau_{h}^{-}$denote $\mathrm{DMU}_{k}$ 's integervalued inputs savings, real-valued inputs savings, integer-valued desirable outputs surpluses, real-valued desirable outputs surpluses, integer-valued undesirable outputs savings, and realvalued undesirable outputs savings, respectively. The other mathematical notations are the same as those in model (4). Model (11) has all the advantages of model (4) and can be used to accurately rank efficient DMUs.

$$
\begin{array}{ll}
\min \quad & \varphi_{k}=1+\frac{\sum_{j=1}^{g} \frac{\xi_{j}^{I-}}{R_{j}^{-}}+\sum_{j=g+1}^{r} \frac{\xi_{j}^{-}}{R_{j}^{-}}+\sum_{p=1}^{o} \frac{\xi_{p}^{I+}}{R_{p}^{+}}+\sum_{p=o+1}^{m} \frac{\xi_{p}^{+}}{R_{p}^{+}}+\sum_{h=1}^{e} \frac{\tau_{h}^{I-}}{R_{h}^{-}}+\sum_{h=e+1}^{t} \frac{\tau_{h}^{-}}{R_{h}^{-}}}{r+m+t} \\
\text { s.t. } \quad & \sum_{i=1, i \neq k}^{q} x_{j i} \lambda_{i} \leq x_{j k}+\xi_{j}^{I-}, \quad j=1,2, \cdots, g, \\
& \sum_{i=1, i \neq k}^{q} x_{j i} \lambda_{i} \leq x_{j k}+\xi_{j}^{-}, \quad j=g+1, g+2, \cdots, r, \\
& \sum_{i=1, i \neq k}^{q} y_{p i} \lambda_{i} \geq y_{p k}-\xi_{p}^{I+}, \quad p=1,2, \cdots, o, \\
& \sum_{i=1, i \neq k}^{q} y_{p i} \lambda_{i} \geq y_{p k}-\xi_{p}^{+}, \quad p=o+1, o+2, \cdots, m, \\
& \sum_{i=1, i \neq k}^{q} z_{h i} \lambda_{i} \leq z_{h k}+\tau_{h}^{I-}, \quad h=1,2, \cdots, e, \\
& \sum_{i=1, i \neq k}^{q} z_{h i} \lambda_{i} \leq z_{h k}+\tau_{h}^{-}, \quad h=e+1, e+2, \cdots, t, \\
& \sum_{i=1, i \neq k}^{q} \lambda_{i}=1, \\
& \lambda_{i}, \xi_{j}^{I-}, \xi_{j}^{-}, \xi_{p}^{I+}, \xi_{p}^{+}, \tau_{h}^{I-}, \tau_{h}^{-} \geq 0 \text { for all } i, j, p, h, \\
& \xi_{j}^{I-} \in \mathbb{Z}, \quad j=1,2, \cdots, g, \\
& \xi_{p}^{I+} \in \mathbb{Z}, \quad p=1,2, \cdots, o, \\
& \tau_{h}^{I-} \in \mathbb{Z}, \quad h=1,2, \cdots, e .
\end{array}
$$

Proposition 4 The Super-RAM-IUDEA model (model (11)) is always feasible.

Proposition $5 \varphi_{k}^{*} \geq 1$, and $\varphi_{k}^{*}>1$ only if $\mathrm{DMU}_{k}$ is efficient.

Proposition 6 The greater $\varphi_{k}^{*}$ is, the better the performance of $\mathrm{DMU}_{k}$ would be.

Proof 1) We prove the Proposition 4 based on the idea of Du, et al. ${ }^{[52]}$. For any $\lambda_{i}^{\dagger}$ $\left(\lambda_{i}^{\dagger} \geq 0\right.$ and $\left.\sum_{i=1, i \neq k}^{q} \lambda_{i}^{\dagger}=1\right)$, let $\xi_{j}^{I-\dagger}=\max \left\{\sum_{i=1, i \neq k}^{q}\left[x_{j i} \lambda_{i}^{\dagger}\right]+1, x_{j k}\right\}-x_{j k} \geq 0$ for $j=$ 
$1,2, \cdots, g, \xi_{j}^{-\dagger}=\max \left\{\sum_{i=1, i \neq k}^{q} x_{j i} \lambda_{i}^{\dagger}, x_{j k}\right\}-x_{j k} \geq 0$ for $j=g+1, g+2, \cdots, r, \xi_{p}^{I+\dagger}=y_{p k}-$ $\min \left\{\left[\sum_{i=1, i \neq k}^{q} y_{p i} \lambda_{i}^{\dagger}\right], y_{p k}\right\} \geq 0$ for $p=1,2, \cdots, o, \xi_{p}^{+\dagger}=y_{p k}-\min \left\{\sum_{i=1, i \neq k}^{q} y_{p i} \lambda_{i}^{\dagger}, y_{p k}\right\} \geq 0$ for $p=o+1, o+2, \cdots, m, \quad \tau_{h}^{I-\dagger}=\max \left\{\sum_{i=1, i \neq k}^{q}\left[z_{h i} \lambda_{i}^{\dagger}\right]+1, z_{h k}\right\}-z_{h k} \geq 0$ for $h=$ $1,2, \cdots, e$, and $\tau_{h}^{-\dagger}=\max \left\{\sum_{i=1, i \neq k}^{q} z_{h i} \lambda_{i}^{\dagger}, z_{h k}\right\}-z_{h k} \geq 0$ for $h=e+1, e+2, \cdots, t$. Then $\left\{\lambda_{i}^{\dagger}, \xi_{j}^{I-\dagger}, \xi_{j}^{-\dagger}, \xi_{p}^{I+\dagger}, \xi_{p}^{+\dagger}, \tau_{h}^{I-\dagger}, \tau_{h}^{-\dagger}\right\}$ is a feasible solution to model (11). [•] denotes the greatest integer less than •. Therefore, the Super-RAM-IUDEA model (model 11) is always feasible.

2) $\varphi_{k}^{*} \geq 1$ because the second part of the right side of the objective function in model (11) is non-negative in value. If $\mathrm{DMU}_{k}$ is inefficient, we can obtain $\sum_{i=1}^{q} x_{j i} \lambda_{i}^{*}<x_{j k}$ for $j=1,2, \cdots, r, \quad \sum_{i=1}^{q} y_{p i} \lambda_{i}^{*}>y_{p k}$ for $p=1,2, \cdots, m$, and $\sum_{i=1}^{q} z_{h i} \lambda_{i}^{*}<z_{h k}$ for $h=1,2, \cdots, t$ from model (4). Thus, $\xi_{j}^{I-*}=\xi_{j}^{-*}=\xi_{p}^{I+*}=\xi_{p}^{+*}=\tau_{h}^{I-*}=\tau_{h}^{-*}=0$ must be the optimal solution for model (11), which implies $\varphi_{k}^{*}=1$. Note that inefficient DMUs do not affect the efficient frontier whether they are in the reference set or not. We have proved that $\varphi_{k}^{*}>1$ only if $\mathrm{DMU}_{k}$ is efficient.

3) The greater $\varphi_{k}^{*}$ (the greater the second part of the right side of the objective function in model 11) is, the greater the distance between $\mathrm{DMU}_{k}$ and the super-efficient frontier is, which indicates that there are more inputs savings, more desirable outputs surpluses, and more undesirable outputs savings in $\mathrm{DMU}_{k}$. Therefore, the greater $\varphi_{k}^{*}$ is, the better the performance of $\mathrm{DMU}_{k}$ would be.

\section{Application}

The transportation industry in China has experienced rapid growth since China's Reform and Opening in 1978. The amount of value-added based on the current prices produced by the transport industry was approximately RMB 4033.7 billion yuan in 2018, which accounted for about $4 \%$ of China's GDP (Gross Domestic Product) ${ }^{[65]}$. However, transport accidents do not disappear although many policies and measures have been implemented to control this problem ${ }^{[66]}$. As shown in Figure 2, the number of transport accidents reached 244937 in 2018 , an increase of $20 \%$ on the previous year. These transport accidents directly caused property damages amount to about RMB 1.4 billion yuan and killed approximately 63194 people ${ }^{[65]}$.

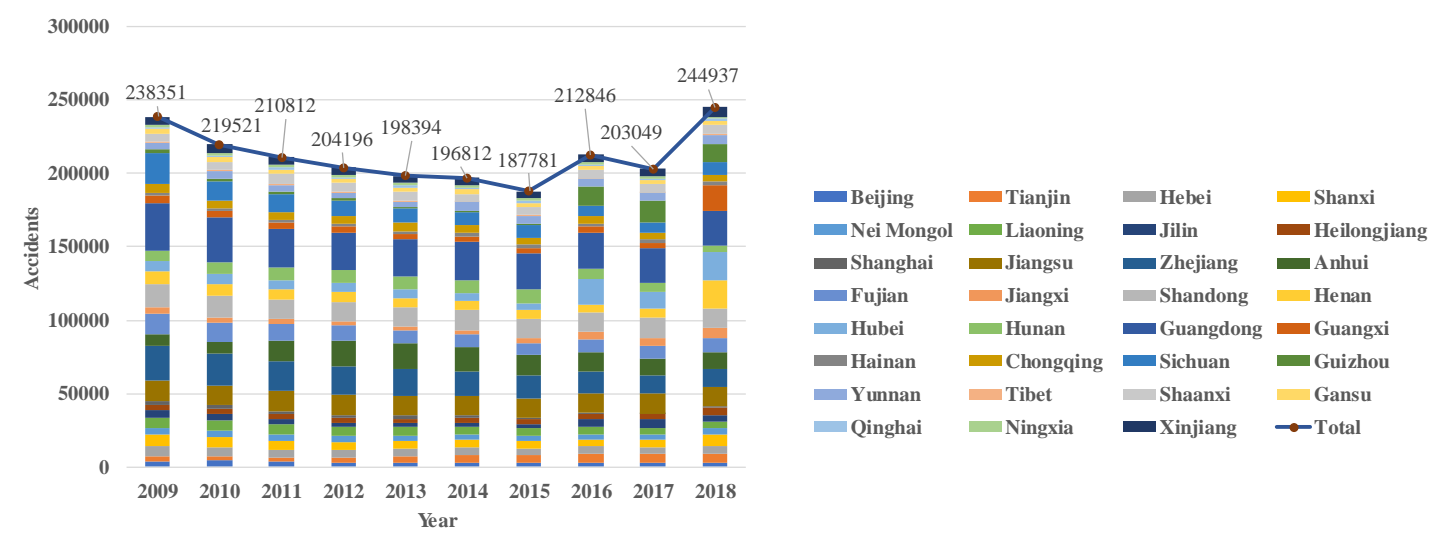

Figure 2 The number of transport accidents in China from 2009 to 2018

In this section, we apply our novel RAM-DEA models to evaluate the performance of China's regional transportation systems (RTSs) considering several integer-valued variables including 
the number of transport accidents (an undesirable output). As far as we know, limited attention has been paid to this topic ${ }^{[67-70]}$. While the number of accidents can only take integer values, these limited studies treated it as a real-valued variable. Besides the integer-valued undesirable output (the number of transport accidents), we also include one integer-valued input (the number of labor), one real-valued input (the amount of fixed capital investment, billion yuan), and one real-valued desirable output (the amount of value-added based on the current prices, billion yuan) in the model. Many scholars took "labor", "fixed capital investment", and "valueadded" into account when measuring the efficiency of China's RTSs because the three variables were vital, but they treated all the variables as real-valued variables. However, as we stated above, the number of labor can only take integer values in reality.

\subsection{Data}

As shown in Table 1, the data about the RTSs of 31 Province / Autonomous region / Municipality in Chinese mainland in 2017 are collected from the National Bureau of Statistics of China ${ }^{[65]}$.

Table 1 Inputs and outputs

\begin{tabular}{|c|c|c|c|c|c|c|c|c|c|}
\hline $\begin{array}{l}\text { Province / } \\
\text { Autonomous } \\
\text { region / } \\
\text { Municipality }\end{array}$ & $x_{1}$ & $x_{2}$ & $y_{1}$ & $z_{1}$ & $\begin{array}{l}\text { Province / } \\
\text { Autonomous } \\
\text { region / } \\
\text { Municipality }\end{array}$ & $x_{1}$ & $x_{2}$ & $y_{1}$ & $z_{1}$ \\
\hline Beijing & 477259 & 112.91 & 120.84 & 3223 & Guangdong & 641733 & 375.96 & 358.09 & 23900 \\
\hline Tianjin & 103586 & 53.70 & 78.04 & 5564 & Guangxi & 148008 & 200.56 & 95.57 & 3843 \\
\hline Hebei & 199378 & 213.55 & 249.79 & 4848 & Hainan & 56464 & 48.60 & 24.89 & 2022 \\
\hline Shanxi & 203859 & 42.55 & 105.21 & 4988 & Chongqing & 231369 & 195.48 & 93.95 & 4573 \\
\hline Nei Mongol & 176748 & 118.02 & 105.00 & 3385 & Sichuan & 308100 & 449.26 & 159.58 & 6947 \\
\hline Liaoning & 310178 & 60.20 & 131.00 & 4793 & Guizhou & 102403 & 233.43 & 107.02 & 14711 \\
\hline Jilin & 123422 & 121.17 & 60.31 & 5485 & Yunnan & 148453 & 374.17 & 36.66 & 5371 \\
\hline Heilongjiang & 217001 & 120.05 & 80.13 & 3623 & Tibet & 6354 & 58.17 & 3.41 & 329 \\
\hline Shanghai & 369045 & 96.03 & 134.45 & 709 & Shaanxi & 227772 & 189.12 & 83.26 & 5819 \\
\hline Jiangsu & 372686 & 289.10 & 309.77 & 13226 & Gansu & 112716 & 95.66 & 29.35 & 2755 \\
\hline Zhejiang & 235280 & 296.75 & 193.82 & 12782 & Qinghai & 42461 & 73.05 & 10.37 & 1128 \\
\hline Anhui & 199510 & 166.78 & 87.54 & 11506 & Ningxia & 32282 & 33.01 & 19.93 & 1569 \\
\hline Fujian & 180441 & 280.89 & 188.97 & 8693 & Xinjiang & 151746 & 197.85 & 66.82 & 5017 \\
\hline Jiangxi & 176305 & 73.46 & 86.63 & 5356 & Max. & 641733.00 & 449.26 & 358.09 & 23900.00 \\
\hline Shandong & 388358 & 395.50 & 326.80 & 13403 & Min. & 6354.00 & 33.01 & 3.41 & 329.00 \\
\hline Henan & 377919 & 249.85 & 216.29 & 6361 & Ave. & 219247.23 & 184.49 & 124.36 & 6549.97 \\
\hline Hubei & 284346 & 293.99 & 142.00 & 11661 & Std. Dev. & 138189.40 & 116.82 & 91.18 & 5078.41 \\
\hline Hunan & 191482 & 210.44 & 149.60 & 5459 & - & - & - & - & - \\
\hline
\end{tabular}

$x_{1}, x_{2}, y_{1}$ and $z_{1}$ denote the "labor", "fixed capital investment", "value-added" and "transport accidents", respectively. As the data related to all the variables in 2019 and the data about "fixed capital investment" in 2018 are not available, we use the dataset in 2017. Note that Nei Mongol is also called Inner Mongolia. The differences between China's RTSs are huge. 
Tibet, the least developed and sparsely populated area in China, has the fewest "labor", the least "value-added", and the fewest "transport accidents" in its RTS. Ningxia, one of the least developed areas in China, has the least "fixed capital investment". Guangdong, the most developed and populous area in China, has the most "labor", the most "value-added", and also the most "transport accidents" in its RTS. Sichuan, whose GDP ranks the 6th and population ranks the 4th in Chinese mainland, has the most "fixed capital investment".

\subsection{Efficiency}

The RAM-IUDEA model (model 4) is used to measure the efficiency of China's RTSs, and the results are shown in Table 2. Ten RTSs are efficient DMUs, i.e., Tianjin, Hebei, Shanxi, Liaoning, Shanghai, Jiangsu, Shandong, Guangdong, Tibet, and Ningxia. Note that the RTSs of Tibet, Ningxia, and Guangdong are regarded as efficient DMUs while the performance of Sichuan's RTS is the worst. The four RTSs have the maximum or minimum values of the selected variables as we mentioned in Subsection 3.1.

Table 2 Efficiency and rankings

\begin{tabular}{lccccc}
\hline $\begin{array}{l}\text { Province / } \\
\text { Autonomous region / }\end{array}$ Eunicipality & Effiency & Ranking & $\begin{array}{l}\text { Province / } \\
\text { Autonomous region / } \\
\text { Municipality }\end{array}$ & Efficiency & Ranking \\
\hline Beijing & 0.8511 & 24 & Hunan & 0.9074 & 17 \\
Tianjin & 1.0000 & 1 & Guangdong & 1.0000 & 1 \\
Hebei & 1.0000 & 1 & Guangxi & 0.8985 & 19 \\
Shanxi & 1.0000 & 1 & Hainan & 0.9808 & 11 \\
Nei Mongol & 0.9502 & 13 & Chongqing & 0.8595 & 23 \\
Liaoning & 1.0000 & 1 & Sichuan & 0.7114 & 31 \\
Jilin & 0.9064 & 18 & Guizhou & 0.7918 & 28 \\
Heilongjiang & 0.9080 & 16 & Yunnan & 0.7243 & 30 \\
Shanghai & 1.0000 & 1 & Tibet & 1.0000 & 1 \\
Jiangsu & 1.0000 & 1 & Shaanxi & 0.8418 & 25 \\
Zhejiang & 0.8009 & 27 & Gansu & 0.9267 & 15 \\
Anhui & 0.8099 & 26 & Qinghai & 0.9711 & 12 \\
Fujian & 0.8709 & 20 & Ningxia & 1.0000 & 1 \\
Jiangxi & 0.9462 & 14 & Xinjiang & 0.8600 & 22 \\
Shandong & 1.0000 & 1 & Max. & 1.0000 & - \\
Henan & 0.8614 & 21 & Min. & 0.7114 & - \\
Hubei & 0.7480 & 29 & Ave. & 0.9073 & - \\
\hline & & & & & \\
\hline
\end{tabular}

The inputs waste, desirable outputs surpluses, and undesirable outputs savings for inefficient China's RTSs are shown in Table $3 . s_{1}^{I-}, s_{2}^{-}, s_{1}^{+}$and $\varsigma_{1}^{I-}$ respectively indicate the labor inputs waste, the fixed capital investment inputs waste, the value-added outputs shortage, and the transport accidents outputs excess. Decision makers can further calculate the targets 
(to eliminate slacks) for DMUs based on the results and equations (5) (10). For example, Beijing's RTS has the largest number of labor to cut, Yunnan's RTS has the largest amount of fixed capital investment to reduce, Qinghai's RTS has the largest amount of value-added to increase, and Guizhou's RTS has the largest number of transport accidents to reduce.

Table 3 Inputs waste, desirable outputs shortage, and undesirable outputs excess for inefficient RTSs

\begin{tabular}{|c|c|c|c|c|}
\hline Province / Autonomous region / Municipality & $s_{1}^{I-}$ & $s_{2}^{-}$ & $s_{1}^{+}$ & $\varsigma_{1}^{I-}$ \\
\hline Beijing & 371627 & 0.623 & - & 215 \\
\hline Nei Mongol & 82632 & 18.173 & - & 603 \\
\hline Jilin & 61786 & 56.443 & - & 3340 \\
\hline Heilongjiang & 140954 & 39.759 & - & 1195 \\
\hline Zhejiang & 76597 & 127.139 & - & 8733 \\
\hline Anhui & 118085 & 80.649 & - & 8973 \\
\hline Fujian & 25281 & 115.095 & - & 4713 \\
\hline Jiangxi & 72746 & - & - & 2378 \\
\hline Henan & 202895 & 62.608 & - & 1991 \\
\hline Hubei & 163330 & 165.089 & - & 8351 \\
\hline Hunan & 64934 & 75.585 & - & 2040 \\
\hline Guangxi & 60740 & 108.139 & - & 1195 \\
\hline Hainan & 20574 & 11.696 & - & 382 \\
\hline Chongqing & 145278 & 104.332 & - & 1948 \\
\hline Sichuan & 174301 & 306.559 & - & 3386 \\
\hline Guizhou & 6816 & 132.003 & - & 11900 \\
\hline Yunnan & 104006 & 328.022 & - & 3563 \\
\hline Shaanxi & 149458 & 106.353 & - & 3347 \\
\hline Gansu & 73591 & 55.237 & - & 1052 \\
\hline Qinghai & 19400 & 31.092 & 3.685 & - \\
\hline Xinjiang & 85377 & 128.011 & - & 2779 \\
\hline Max. & 371627 & 328.022 & 3.685 & 11900 \\
\hline Min. & 6816 & 0.623 & 3.685 & 215 \\
\hline Ave. & 105733.714 & 102.630 & 3.685 & 3604.200 \\
\hline
\end{tabular}

The results show that our novel RAM-IUDEA model is able to generate the integer-valued slacks (and targets) for integer-valued variables. This advantage of our model is important for managers because it makes it simple for them to make and implement an efficiency improvement plan. Moreover, integer-valued DEA models are more reliable than real-valued DEA models as we explained in Section 1 and Section 2. 


\subsection{Super-Efficiency}

In order to differentiate efficient China's RTSs the Super-RAM-IUDEA model (model (11)) is applied. As shown in Table 4, the performance of Hebei's RTS is the best, followed by Shanghai, Guangdong, Tibet, Ningxia, Shandong, Shanxi, Jiangsu, Liaoning, and Tianjin.

Table 4 Super-efficiency and rankings

\begin{tabular}{lccccc}
\hline $\begin{array}{l}\text { Province / } \\
\text { Autonomous region / } \\
\text { Municipality }\end{array}$ & Efficiency & Ranking & $\begin{array}{l}\text { Province / } \\
\text { Autonomous region / } \\
\text { Municipality }\end{array}$ & Efficiency & Ranking \\
\hline Tianjin & 1.0058 & 10 & Jiangsu & 1.0101 & 8 \\
Hebei & 1.0753 & 1 & Shandong & 1.0114 & 6 \\
Shanxi & 1.0102 & 7 & Guangdong & 1.0243 & 3 \\
Liaoning & 1.0081 & 9 & Tibet & 1.0229 & 4 \\
Shanghai & 1.0342 & 2 & Ningxia & 1.0135 & 5 \\
\hline
\end{tabular}

Table 5 shows the inputs savings, desirable outputs surpluses, and undesirable outputs savings for efficient RTSs. $\xi_{1}^{I-}, \xi_{1}^{-}, \xi_{1}^{+}$and $\tau_{1}^{I-}$ represent the labor inputs savings, fixed capital investment inputs savings, value-added outputs surpluses, and transport accidents outputs savings, respectively. The results not only show the rankings of efficient RTSs but also enable decision makers to identify the strengths of efficient RTSs. Moreover, the results are reliable because the models can generate integer values for integer-valued variables and real values for real-valued variables.

Table 5 Inputs savings, desirable outputs surpluses, and undesirable outputs savings for efficient RTSs

\begin{tabular}{lcccc}
\hline Province / Autonomous region / Municipality & $\xi_{1}^{I-}$ & $\xi_{2}^{-}$ & $\xi_{1}^{+}$ & $\tau_{1}^{I-}$ \\
\hline Tianjin & - & 9.718 & - & - \\
Hebei & - & - & 100.860 & 400 \\
Shanxi & - & 16.957 & - & - \\
Liaoning & - & - & 11.548 & - \\
Shanghai & - & - & - & 3229 \\
Jiangsu & - & - & 14.294 & - \\
Shandong & - & - & 16.229 & - \\
Guangdong & - & - & 34.418 & - \\
Tibet & 32325 & - & - & 963 \\
Ningxia & - & 22.521 & - & - \\
\hline
\end{tabular}

Finally, as shown in Table 6, we get the performance rankings of China's RTSs. 
Table 6 Rankings

\begin{tabular}{lccccc}
\hline $\begin{array}{l}\text { Province / } \\
\text { Autonomous region / } \\
\text { Municipality }\end{array}$ & Efficiency & Ranking & $\begin{array}{c}\text { Province / } \\
\text { Autonomous region / } \\
\text { Municipality }\end{array}$ & Efficiency & Ranking \\
\hline Hebei & 1.0753 & 1 & Hunan & 0.9074 & 17 \\
Shanghai & 1.0342 & 2 & Jilin & 0.9064 & 18 \\
Guangdong & 1.0243 & 3 & Guangxi & 0.8985 & 19 \\
Tibet & 1.0229 & 4 & Fujian & 0.8709 & 20 \\
Ningxia & 1.0135 & 5 & Henan & 0.8614 & 21 \\
Shandong & 1.0114 & 6 & Xinjiang & 0.8600 & 22 \\
Shanxi & 1.0102 & 7 & Chongqing & 0.8595 & 23 \\
Jiangsu & 1.0101 & 8 & Beijing & 0.8511 & 24 \\
Liaoning & 1.0081 & 9 & Shaanxi & 0.8418 & 25 \\
Tianjin & 1.0058 & 10 & Anhui & 0.8099 & 26 \\
Hainan & 0.9808 & 11 & Zhejiang & 0.8009 & 27 \\
Qinghai & 0.9711 & 12 & Guizhou & 0.7918 & 28 \\
Nei Mongol & 0.9502 & 13 & Hubei & 0.7480 & 29 \\
Jiangxi & 0.9462 & 14 & Yunnan & 0.7243 & 30 \\
Gansu & 0.9267 & 15 & Sichuan & 0.7114 & 31 \\
Heilongjiang & 0.9080 & 16 & - & - & - \\
\hline
\end{tabular}

\subsection{Discussion}

Decision makers should take undesirable outputs into account when measuring the performance of DMUs with undesirable outputs. Otherwise, the results may be problematic. If we do not consider the "transport accidents" when measuring the efficiency of China's RTSs, the results would be inaccurate as shown in Table 7. For example, the RTS of Shanghai is regarded as an inefficient DMU if we apply the integer-valued super-efficiency RAM-DEA model without undesirable outputs (Super-RAM-IDEA). Shanghai is the most densely populated area and the amount of value-added by Shanghai's RTS ranks the 11th in Chinese mainland. But the number of transport accidents in Shanghai is only 709, which is less than the other provinces except Tibet. Therefore, the ranking of Shanghai's RTS should not be only the 18th (the results obtained from the Super-RAM-IDEA model).

In addition, decision makers cannot simply treat integer-valued variables as reals and round the real-valued solutions to integers. If we apply the real-valued super-efficiency RAM-DEA model with undesirable outputs (Super-RAM-UDEA) to measure the super-efficiency of DMUs with integer-valued variables, the resulting inputs savings, desirable outputs surpluses, and undesirable outputs savings for efficient DMUs may be wrong. Similarly, if we apply the realvalued RAM-DEA model with undesirable output (RAM-UDEA) to measure the efficiency of DMUs with integer-valued variables, the resulting inputs waste, desirable outputs shortage, and undesirable outputs excess for inefficient DMUs may be also erroneous. The results obtained from RAM-UDEA and Super-RAM-UDEA models are shown in Table 8 and Table 9, where 
"N" indicates that the real-valued solutions for the RTS obtained from the RAM-UDEA or Super-RAM-UDEA models cannot be rounded to our integer-valued solutions.

Table 7 Rankings obtained from our Super-RAM-IUDEA model and the Super-RAM-IDEA model

\begin{tabular}{lcclcc}
\hline Province / & Super- & Super- & Province / & Super- & Super- \\
Autonomous region / & RAM- & RAM- & Autonomous region / & RAM- & RAM- \\
Municipality & IUDEA & IDEA & Municipality & IUDEA & IDEA \\
\hline Beijing & 24 & 28 & Hubei & 29 & 29 \\
Tianjin & 10 & 9 & Hunan & 17 & 16 \\
Hebei & 1 & 1 & Guangdong & 3 & 2 \\
Shanxi & 7 & 7 & Guangxi & 19 & 21 \\
Nei Mongol & 13 & 13 & Hainan & 11 & 10 \\
Liaoning & 9 & 8 & Chongqing & 23 & 26 \\
Jilin & 18 & 14 & Sichuan & 31 & 31 \\
Heilongjiang & 16 & 20 & Guizhou & 28 & 19 \\
Shanghai & 2 & 18 & Yunnan & 30 & 30 \\
Jiangsu & 8 & 5 & Tibet & 4 & 4 \\
Zhejiang & 27 & 23 & Shaanxi & 25 & 27 \\
Anhui & 26 & 22 & Gansu & 15 & 15 \\
Fujian & 20 & 17 & Qinghai & 12 & 12 \\
Jiangxi & 14 & 11 & Ningxia & 5 & 3 \\
Shandong & 6 & 6 & Xinjiang & 22 & 24 \\
Henan & 21 & 25 & - & - & - \\
\hline
\end{tabular}

The results show that there are huge differences between the results for China's RTSs efficiency measurement obtained from our integer-valued models and those resulting from realvalued models. As to the inefficient RTSs, about $76 \%$ of RTSs' real-valued solutions obtained from the RAM-UDEA cannot be rounded to the integer-valued solutions. For instance, the labor inputs slack in the RTS of Heilongjiang should be 140954 (as shown in Table 3), but the result obtained from the Super-RAM-UDEA model is 140956.800 (as shown in Table 8). The labor inputs savings in the RTS of Tibet should be 32325 (as shown in Table 5), but the result obtained from the Super-RAM-UDEA model is 32324.190 (as shown in Table 9). The reason for the differences is that the PPS (as shown in formula (3)) for DMUs could be changed if decision makers do not consider their integer-valued variables when measuring efficiency. Therefore, our integer-valued models are better than traditional real-valued models.

As stated above, the results may be problematic if decision makers did not take undesirable outputs into account when measuring the performance of DMUs with undesirable outputs or restrict variables to integers when measuring the performance of DMUs with integer-valued variables. The proposed RAM-IUDEA and Super-RAM-IUDEA models can be used to deal with integer-valued variables and undesirable outputs, which can help decision makers accurately 
measure the efficiency and super-efficiency of DMUs.

Table 8 Inputs waste, desirable outputs shortage, and undesirable outputs excess

\begin{tabular}{|c|c|c|c|c|}
\hline Province / Autonomous region / Municipality & $s_{1}^{I-}$ & $s_{2}^{-}$ & $s_{1}^{+}$ & $\varsigma_{1}^{I-}$ \\
\hline$\underline{\text { Beijing }}$ & 371620.800 & 0.642 & - & 214.498 \\
\hline Nei Mongol & 82624.630 & 18.193 & - & 602.459 \\
\hline Jilin & 61785.890 & 56.444 & - & 3339.971 \\
\hline Heilongjiang & 140956.800 & 39.757 & - & 1195.235 \\
\hline Zhejiang & 76589.210 & 127.161 & - & 8732.424 \\
\hline$\underline{\text { Anhui }}$ & 118079.100 & 80.667 & - & 8972.529 \\
\hline$\underline{\text { Fujian }}$ & 25275.910 & 115.110 & - & 4712.610 \\
\hline$\underline{\text { Jiangxi }}$ & 72760.360 & - & - & 2377.760 \\
\hline Henan & 202893.700 & 62.612 & - & 1990.884 \\
\hline$\underline{\text { Hubei }}$ & 163325.600 & 165.102 & - & 8350.646 \\
\hline$\underline{\text { Hunan }}$ & 64936.800 & 75.583 & - & 2040.231 \\
\hline Guangxi & 60739.740 & 108.140 & - & 1194.980 \\
\hline$\underline{\text { Hainan }}$ & 20576.340 & 11.694 & - & 382.245 \\
\hline Chongqing & 145278.400 & 104.332 & - & 1948.090 \\
\hline$\underline{\text { Sichuan }}$ & 174299.900 & 306.564 & - & 3385.864 \\
\hline Guizhou & 6811.200 & 132.017 & - & 11899.640 \\
\hline Yunnan & 104009.200 & 328.020 & - & 3563.343 \\
\hline$\underline{\text { Shaanxi }}$ & 149452.500 & 106.368 & - & 3346.585 \\
\hline Gansu & 73586.160 & 55.251 & - & 1051.622 \\
\hline Qinghai & 19400.170 & 31.092 & 3.685 & - \\
\hline Xinjiang & 85377.460 & 128.011 & - & 2779.105 \\
\hline
\end{tabular}

Table 9 Inputs savings, desirable outputs surpluses, and undesirable outputs savings

\begin{tabular}{lcccclcccc}
\hline $\begin{array}{l}\text { Province / } \\
\text { Autonomous } \\
\text { region / } \\
\text { Municipality }\end{array}$ & $\xi_{1}^{I-}$ & $\xi_{2}^{-}$ & $\xi_{1}^{+}$ & $\tau_{1}^{I-}$ & $\begin{array}{l}\text { Autonomous } \\
\text { region / } \\
\text { Municipality }\end{array}$ & $\xi_{1}^{I-}$ & $\xi_{2}^{-}$ & $\xi_{1}^{+}$ & $\tau_{1}^{I-}$ \\
\hline Tianjin & & & & & & & & & \\
Hebei & - & - & 100.864 & 399.774 & Shandong & - & - & 14.294 & - \\
Shanxi & - & 16.957 & - & - & Guangdong & - & - & 34.418 & - \\
Liaoning & - & - & 11.548 & - & Tibet & 32324.190 & - & - & 962.888 \\
Shanghai & - & - & - & 3228.896 & Ningxia & - & 22.521 & - & - \\
\hline
\end{tabular}

\section{Conclusion}

Non-radial DEA models, i.e., additive DEA, SBM, and RAM, have greater discriminatory ability than radial DEA models. However, integer-valued additive DEA models cannot generate 
efficiency scores for DMUs and integer-valued SBM-DEA models are nonlinear programming even after Charnes-Cooper transformation. Therefore, we develop an integer-valued superefficiency RAM-DEA model that is linear programming and can generate efficiency scores. Moreover, the model can handle undesirable outputs that can significantly affect the DEA efficiency measurement of DMUs.

The main contributions of this study are as follows. 1) An integer-valued super-efficiency RAM-DEA model with undesirable outputs is proposed, which can be used to accurately rank efficient DMUs with integer-valued variables and undesirable outputs. 2) The proposed model is applied to evaluate the efficiency of China's regional transportation systems (RTSs) considering the number of transport accidents (an undesirable output). The results help decision makers improve the performance of inefficient RTSs and analyze the strengths of efficient RTSs. The empirical study shows that it is necessary to consider integer-valued variables and undesirable outputs when measuring efficiency.

We also propose an integer-valued RAM-DEA model with undesirable outputs besides our integer-valued super-efficiency RAM-DEA model. However, the objective function of this model is to maximize the slacks of the selected variables so that the resulting targets for inefficient DMUs are the farthest. In the future, we will research the RAM-DEA approach to find the closest targets for DMUs.

The integer-valued super-efficiency RAM-DEA model is proposed under the assumption of strong disposability of undesirable outputs. This assumption is based on our belief that the undesirable output (the number of transport accidents) in our case study can be disposed of. However, there are some undesirable outputs which may be weakly disposable, e.g., the amount of carbon emissions. In the future, it is necessary to develop an integer-valued super-efficiency RAM-DEA model considering both strongly and weakly disposable undesirable outputs at the same time.

Acknowledgements The authors thank the editor and the reviewers for their valuable comments. The authors would also like to thank Professor Guoqing Chen at Inner Mongolia University for providing useful suggestions on the paper.

\section{References}

[1] Zelenyuk V. Aggregation of inputs and outputs prior to data envelopment analysis under big data. European Journal of Operational Research, 2020, 282(1): 172-187.

[2] Yu M, Chen L. Evaluation of efficiency and technological bias of tourist hotels by a meta-frontier DEA model. Journal of the Operational Research Society, 2019, 12(4): 1-15.

[3] Guner S, Coskun E. Estimating the operational and service efficiency of bus transit routes using a non-radial DEA approach. EURO Journal on Transportation and Logistics, 2019, 8(3): 249-268.

[4] Chen P, Yu M, Shih J, et al. A reassessment of the Global Food Security Index by using a hierarchical data envelopment analysis approach. European Journal of Operational Research, 2019, 272(2): 687-698.

[5] Charnes A, Cooper W W, Rhodes E, et al. Measuring the efficiency of decision making units. European Journal of Operational Research, 1978, 2(6): 429-444.

[6] Banker R D, Charnes A, Cooper W W, et al. Some models for estimating technical and scale inefficiencies in data envelopment analysis. Management Science, 1984, 30(9): 1078-1092.

[7] Caldas P, Ferreira D C, Dollery B, et al. Are there scale economies in urban waste and wastewater municipal services? A non-radial input-oriented model applied to the Portuguese local government. Journal of Cleaner Production, 2019, 219: 531-539. 
[8] Chen X, Wu G, Li D, et al. Efficiency measure on the truck restriction policy in China : A non-radial data envelopment model. Transportation Research Part A - Policy and Practice, 2019, 129: 140-154.

[9] Zhou Z, Wu H, Song P, et al. Measuring the resource and environmental efficiency of industrial water consumption in China: A non-radial directional distance function. Journal of Cleaner Production, 2019, 240: 1-11.

[10] Charnes A, Cooper W W, Golany B, et al. Foundations of data envelopment analysis for Pareto-Koopmans efficient empirical production functions. Journal of Econometrics, 1985, 30(1-2): 91-107.

[11] Tone K. A slacks-based measure of efficiency in data envelopment analysis. European Journal of Operational Research, 2001, 130(3): 498-509.

[12] Cooper W W, Park K S, Pastor J T, et al. RAM: A range adjusted measure of inefficiency for use with additive models, and relations to other models and measures in DEA. Journal of Productivity Analysis, 1999, 11(1): 5-42.

[13] Yu S. Benchmarking and performance evaluation towards the sustainable development of regions in Taiwan: A minimum distance-based measure with undesirable outputs in additive DEA. Social Indicators Research, 2019, 144(3): 1323-1348.

[14] Arteaga F J, Tavana M, Caprio D D, et al. A dynamic multi-stage slacks-based measure data envelopment analysis model with knowledge accumulation and technological evolution. European Journal of Operational Research, 2019, 278(2): 448-462.

[15] Khezrimotlagh D, Salleh S, Mohsenpour Z, et al. A new robust mixed integer-valued model in DEA. Applied Mathematical Modelling, 2013, 37(24): 9885-9897.

[16] Taleb M, Ramli R, Khalid R, et al. Developing a two-stage approach of super efficiency slack-based measure in the presence of non-discretionary factors and mixed integer-valued data envelopment analysis. Expert Systems with Applications, 2018, 103: 14-24.

[17] Lozano S, Villa G. Data envelopment analysis of integer-valued inputs and outputs. Computers \& Operations Research, 2006, 33(10): 3004-3014.

[18] Chen C H, Liu H H, Liu B, et al. Measuring the performance of pallet rental companies: Integer-valued DEA models with generalized reference sets. IEEE Access, 2020, 8: 3374-3386.

[19] Kuosmanen T, Matin R K. Theory of integer-valued data envelopment analysis. European Journal of Operational Research, 2009, 192(2): 658-667.

[20] Aida K, Cooper W W, Pastor J T, et al. Evaluating water supply services in Japan with RAM: A rangeadjusted measure of inefficiency. Omega, 1998, 26(2): 207-232.

[21] Steinmann L, Zweifel P. The range adjusted measure (RAM) in DEA: Comment. Journal of Productivity Analysis, 2001, 15(2): 139-144.

[22] Cooper W W, Park K S, Pastor J T, et al. The range adjusted measure (RAM) in DEA: A response to the comment by Steinmann and Zweifel. Journal of Productivity Analysis, 2001, 15(2): 145-152.

[23] Sueyoshi T, Sekitani K. Measurement of returns to scale using a non-radial DEA model: A range-adjusted measure approach. European Journal of Operational Research, 2007, 176(3): 1918-1946.

[24] Cooper W W, Pastor J T, Borras F, et al. BAM: A bounded adjusted measure of efficiency for use with bounded additive models. Journal of Productivity Analysis, 2011, 35(2): 85-94.

[25] Chiu C, Chiu Y, Fang C, et al. The performance of commercial banks based on a context-dependent range-adjusted measure model. International Transactions in Operational Research, 2014, 21(5): 761-775.

[26] Avkiran N K, McCrystal A. Dynamic network range-adjusted measure vs. dynamic network slacks-based measure. Journal of The Operations Research Society of Japan, 2014, 57(1): 1-14.

[27] Tavassoli M, Badizadeh T, Saen R F, et al. Performance assessment of airlines using range-adjusted measure, strong complementary slackness condition, and discriminant analysis. Journal of Air Transport Management, 2016, 54: 42-46.

[28] Liu X, Zhu Q, Chu J, et al. Environmental performance and benchmarking information for coal-fired power plants in China: A DEA approach. Computational Economics, 2019, 54(4): 1287-1302.

[29] Li Y, Wang Y, Cui Q, et al. Energy efficiency measures for airlines: An application of virtual frontier dynamic range adjusted measure. Journal of Renewable and Sustainable Energy, 2016, 8(1): 1-14.

[30] Wanke P, Barros C P. Efficiency in Latin American airlines: A two-stage approach combining virtual frontier dynamic DEA and simplex regression. Journal of Air Transport Management, 2016, 54: 93-103.

[31] Li Y, Cui Q. Airline efficiency with optimal employee allocation: An input-shared network range adjusted 
measure. Journal of Air Transport Management, 2018, 73: 150-162.

[32] Walheer B. Output, input, and undesirable output interconnections in data envelopment analysis: Convexity and returns-to-scale. Annals of Operations Research, 2020, 284(1): 447-467.

[33] Wang H, Pan C, Wang Q, et al. Assessing sustainability performance of global supply chains: An inputoutput modeling approach. European Journal of Operational Research, 2020. https://www.sciencedirect. com/science/article/pii/S0377221720300941.

[34] Sueyoshi T, Goto M. Should the US clean air act include $\mathrm{CO}_{2}$ emission control?: Examination by data envelopment analysis. Energy Policy, 2010, 38(10): 5902-5911.

[35] Sueyoshi T, Goto M. Methodological comparison between two unified (operational and environmental) efficiency measurements for environmental assessment. European Journal of Operational Research, 2011, 210(3): 684-693.

[36] Ramli N A, Munisamy S. Eco-efficiency in greenhouse emissions among manufacturing industries: A range adjusted measure. Economic Model, 2015, 47: 219-227.

[37] Wang K, Yu X. Industrial energy and environment efficiency of Chinese cities: An analysis based on rangeadjusted measure. International Journal of Information Technology and Decision Making, 2017, 16(4): 1023-1042.

[38] Wang W, Yu B, Yan X, et al. Estimation of innovation's green performance: A range-adjusted measure approach to assess the unified efficiency of China's manufacturing industry. Journal of Cleaner Production, 2017, 149: 919-924.

[39] Cui Q, Li Y. Airline environmental efficiency measures considering materials balance principles: An application of a network range-adjusted measure with weak-G disposability. Journal of Environmental Planning and Management, 2018, 61(13): 2298-2318.

[40] Meng M, Fu Y, Wang L, et al. Low-carbon economy efficiency analysis of China's provinces based on a range-adjusted measure and data envelopment analysis model. Journal of Cleaner Production, 2018, 199: 643-650.

[41] Kang Y, Xie B, Wang J, et al. Environmental assessment and investment strategy for China's manufacturing industry: A non-radial DEA based analysis. Journal of Cleaner Production, 2018, 175: 501-511.

[42] Miao Z, Chen X, Baležentis T, et al. Atmospheric environmental productivity across the provinces of China: Joint decomposition of range adjusted measure and Luenberger productivity indicator. Energy Policy, 2019, 132: 665-677.

[43] Eftekharian P, Homayonifar M, Kazemi M, et al. Environmental efficiency of energy intensive industries in Iran: Range Adjusted Measure. Journal of Energy Planning and Policy Research, 2019, 5(16): 33-66.

[44] Wang Q, Yuan Q. Energy-saving and emission reduction potential of the tobacco industry: A case study of China's 18 cigarette enterprises. Journal of Cleaner Production, 2020. https://doi.org/10.1016/ j.jclepro.2019.118429.

[45] Chen Z, Zhao W, Li F, Wang W. Congestion assessment for the Belt and Road countries considering carbon emission reduction. Journal of Cleaner Production, 2020. https://doi.org/10.1016/j.jclepro.2019.118405.

[46] Yuan Q Q, Cheng C F C, Wang J Y, et al. Inclusive and sustainable industrial development in China: An efficiency-based analysis for current status and improving potentials. Applied Energy, 2020. https://doi.org/10.1016/j.apenergy.2020.114876.

[47] Ren J, Chen C, Gao B, et al. Performance evaluation of pallet rental companies: A non-oriented superefficiency integer-valued DEA model. IEEE Access, 2019, 7: 151628-151637.

[48] Lin R, Yang W, Huang H, et al. A modified slacks-based super-efficiency measure in the presence of negative data. Computers \& Industrial Engineering, 2019, 135: 39-52.

[49] Andersen P, Petersen N C. A procedure for ranking efficient units in data envelopment analysis. Management Science, 1993, 39(10): 1261-1264.

[50] Gokgoz F, Erkul E. Investigating the energy efficiencies of European countries with super efficiency model and super SBM approaches. Energy Efficiency, 2019, 12(3): 601-618.

[51] Ma X, Wang C, Yu Y, et al. Ecological efficiency in China and its influencing factors - A super-efficient SBM metafrontier-Malmquist-Tobit model study. Environmental Science and Pollution Research, 2018, 25(21): 20880-20898.

[52] Du J, Chen C, Chen Y, et al. Additive super-efficiency in integer-valued data envelopment analysis. European Journal of Operational Research, 2012, 218(1): 186-192. 
[53] Guo I, Lee H, Lee D, et al. An integrated model for slack-based measure of super-efficiency in additive DEA. Omega, 2017, 67: 160-167.

[54] Yu S, Hsu C. A unified extension of super-efficiency in additive data envelopment analysis with integervalued inputs and outputs: An application to a municipal bus system. Annals of Operations Research, 2020, 287(1): 515-535.

[55] Tone K. A slacks-based measure of super-efficiency in data envelopment analysis. European Journal of Operational Research, 2001, 143(1): 32-41.

[56] Tran T H, Mao Y, Nathanail C P, et al. Integrating slacks-based measure of efficiency and super-efficiency in data envelopment analysis. Omega, 2019, 85: 156-165.

[57] Chen F, Zhao T, Wang J, et al. The evaluation of energy-environmental efficiency of China's industrial sector: Based on Super-SBM model. Clean Technologies and Environmental Policy, 2019, 21(7): 1397-1414.

[58] Chen C M, Du J, Huo J, et al. Undesirable factors in integer-valued DEA: Evaluating the operational efficiencies of city bus systems considering safety records. Decision Support Systems, 2012, 54(1): 330-335.

[59] Färe R, Grosskopf S, Lovell C A, et al. Multilateral productivity comparisons when some outputs are undesirable: A nonparametric approach. The Review of Economics and Statistics, 1989, 71(1): 90-98.

[60] Chung Y, Fare R, Grosskopf S, et al. Productivity and undesirable outputs: A Directional Distance Function Approach. Journal of Environmental Management, 1997, 51(3): 229-240.

[61] Layer K, Johnson A L, Sickles R C, et al. Direction selection in stochastic directional distance functions. European Journal of Operational Research, 2020, 280(1): 351-364.

[62] Seiford L M, Zhu J. Modeling undesirable factors in efficiency evaluation. European Journal of Operational Research, 2002, 142(1): 16-20.

[63] Halkos G, Petrou K N. Treating undesirable outputs in DEA: A critical review. Economic Analysis and Policy, 2019, 62: 97-104.

[64] Du J, Liang L, Zhu J, et al. A slacks-based measure of super-efficiency in data envelopment analysis: A comment. European Journal of Operational Research, 2010, 204(3): 694-697.

[65] National Bureau of Statistics of China. China statistical yearbook, 2020. http://data.stats.gov.cn/ easyquery.htm?cn=E0103.

[66] Liu X, Turla T, Zhang Z, et al. Accident-cause-specific risk analysis of rail transport of hazardous materials. Transportation Research Record, 2018, 2672(10): 176-187.

[67] Chiu Y, Huang C, Ma C, et al. Assessment of China transit and economic efficiencies in a modified valuechains DEA model. European Journal of Operational Research, 2011, 209(2): 95-103.

[68] Pal D, Mitra S K. An application of the directional distance function with the number of accidents as an undesirable output to measure the technical efficiency of state road transport in India. Transportation Research Part A - Policy and Practice, 2016, 93: 1-12.

[69] Tian N, Tang S, Che A, et al. Measuring regional transport sustainability using super-efficiency SBM-DEA with weighting preference. Journal of Cleaner Production, 2020, 242: 1-11.

[70] Stefaniec A, Hosseini K, Xie J, et al. Sustainability assessment of inland transportation in China: A triple bottom line-based network DEA approach. Transportation Research Part D - Transport and Environment, 2020. https://doi.org/10.1016/j.trd.2020.102258. 